\title{
Providing a New Approach in Engineering Economics
}

\author{
Hossein Jafari ${ }^{1}$, Farzane Hosseinieh Farahani ${ }^{2}$ \\ ${ }^{1,2}$ Young Researchers and Elite Club, Arak Branch, Islamic Azad Univercity, Arak, Iran
}

\begin{abstract}
Engineering economy set of mathematical techniques for economic evaluation of investment projects that present value and internal rate of return method are among the most important of these methods. Managers and investors have many reasons to using internal rate of return greater willingness shown. This is while the serious problems associated with using internal rate of return method. In recent years, several articles have been published in order to fix the way in which we can approach the Magni in 2010. The aim of this paper is to simplify and facilitate the model is, in other words, by eliminating some of the most simple and straightforward algorithm to calculate the rate of return Magni way we present period.
\end{abstract}

Keywords: NPV, IRR, Project Analysis, AIRR

\section{Introduction and Problem Definition}

The best action of any company adopt goals that will maximize corporate value. Shareholders interested in this because this is affecting their efficiency. Return that shareholders are demanding, accounting efficiencies and ROI in the market. [1],[5] So the techniques that capital projects to properly assess the impact on shareholder value.[3] Rate of return method (IRR) common practice to assess cash flows (both deterministic, probabilistic and fuzzy) is. In fact, managers want to know the internal rate of return of capital compared with a minimum rate of absorption (such as bank rate) to assess the potential and economic efficiency projects, because the operation is very simple and understandable, while the rate of return method Internal capital problems can be summarized as follows:

The lack of a real rate of return, in some cases, the possibility of creating negative real rates, in some cases, the rise rate of return imaginary (complex) in many cases, there is a contradiction between the results of using this method (IRR) and present value method Capital (NPV).

\section{Background Research}

Among the tested solutions to solve these problems can be mentioned in subsequent articles, each with an internal rate of return of capital and its problems have to search.[8] Norstrøm, cash flows included a non-negative rate of return is assessed, and does not justify the negative rates.[5] Several projects with respect to the flow rate can be detected and also for economic projects has a unique rate should be the model for a series of transactions (flows) comply, the case of such a possibility does not exist. [6] Magni, in 2010 to discuss a different approach showed that the internal rate of return on all courses Does not stand still, so that by calculating the simple arithmetic average rate of return of individual courses, can all be remedied weaknesses investment internal rate of return method and the results are quite consistent with the balance method. [9] The average internal rate of return method (AIRR) has extraordinary features than the old method of internal rate of return (IRR), which among them are: lack of complex rates, the simplicity of the calculation, the exact compatibility with The present value, better reflect the profitability of the project and a financial Holly. [2]

\section{Internal Rate of Return}

A cash flow stream is a finite or infinite sequence $\mathrm{X}=$ $\left(\mathrm{x}_{0}, \mathrm{x}_{1}, \ldots\right)$ of monetary values. The monetary amount received initially is $x_{0}$, and the amount received after period $t$ is $x_{t}$. For a finite stream $X=\left(x_{0}, x_{1}, \ldots, x_{n}\right)$, we assume the horizon $n$ is chosen so that $x_{n} \neq 0$. The net present value $\mathrm{PV}(\mathrm{X} \mid \mathrm{r})$ of a cash flow stream $\mathrm{X}$ at interest rate $\mathrm{r}$ is given by:

$$
P V(X \mid r)=\sum_{t=0}^{n} \frac{x_{t}}{(1+r)^{t}}
$$

defined for proper interest rates $\mathrm{r}>-1$. For a cash flow stream $X$, let IRR $(X)$ be the set of all interest rates $r$ which make $P V(X \mid r)=0$. (Note that $\operatorname{IRR}(X)$ cannot contain -1 because $\mathrm{PV}(\mathrm{X} \mid \mathrm{r}=-1)$ is undefined.) For finite streamsX = $\left(\mathrm{x}_{0}, \mathrm{x}_{1}, \ldots, \mathrm{x}_{\mathrm{n}}\right)$, the present value function $\mathrm{PV}(\mathrm{X} \mid \mathrm{r})$ is a degree-n polynomial in $(1+r)^{-1}$, so $\operatorname{IRR}(X)$ can contain anywhere from 0 to $n$ distinct values. If $r \in \operatorname{IRR}(X)$, then we will call $r$ an internal rate of return for $X$.

As is well known, for conventional cash flows $X$ that are negative for the first few periods but positive thereafter, the internal rate of return exists and is unique. Moreover, the internal rate of return is the largest interest rate at which the cash flow shows a discounted net profit. So if $\operatorname{IRR}(X)$ exceeds the available market rate of interest $r$, then $\mathrm{PV}(\mathrm{X} \mid \mathrm{r})>0$ and the investment which generates the cash flow $X$ is worthwhile. Conversely, if the internal rate of return is smaller than the market rate $r$, then one is better off investing at the market rate $r$. This is the fundamental justification for the use of internal rate of return. [4]

\section{Average approach of Internal Rate of Return of Capital (AIRR)}

Magni in an article, by providing a solution named average approach of Internal Rate of Return of Capital, has tried to solve the problems of IRR method, with the attitude that in 


\section{International Journal of Science and Research (IJSR) \\ ISSN (Online): 2319-7064}

Index Copernicus Value (2013): 6.14 | Impact Factor (2015): 6.391

Hazen approach, rates of return during the different periods does not stand still. In what follows all necessary cases for the introduction of approach has been provided .[9]

Theorem(1):Consider the desired investment flow $C=$ $\left(c_{0}, c_{1}, \ldots, c_{n-1}\right)$, then the following equation can be expressed:

$$
P V(X \mid r)=\sum_{t=1}^{n}\left(R_{t}-r \cdot c_{t-1}\right) \cdot(1+r)^{-t}
$$

By putting the relationship in equation (2) the following equation is obtained:

$$
P V(X \mid r)=\sum_{t=1}^{n} c_{t-1}\left(k_{t}-r\right) \cdot(1+r)^{-t}
$$

If in equation (3) instead of interest rates in the period $\mathrm{t}\left(k_{t}\right.$ ) average interest rate $(\bar{k})$ is used, equation (4, 5 and 6) will be obtained.

$$
\begin{aligned}
& P V(X \mid r)=\sum_{t=1}^{n} c_{t-1}\left(k_{t}-r\right) \cdot(1+r)^{-t}= \\
& \sum_{t=1}^{n} c_{t-1}(\bar{k}-r) \cdot(1+r)^{-t} \\
& \bar{k}=\sum_{t=1}^{n} \frac{k_{t} \cdot c_{t-1} \cdot(1+r)^{-t}}{c_{t-1} \cdot(1+r)^{-t}} \\
& \bar{k}=r+\frac{P V(X \mid r) \cdot(1+r)}{p V(c \mid r)}
\end{aligned}
$$

Conclusion(1): If in the previous theorem consider the desired investment flow $C=\left(c_{0}=-x_{0}, c_{1}=-x_{0}(1+\right.$ $r, c 2=-x 01+r 2, c 3=-x 01+r 3 \ldots, \quad c n-1=-x 01+r n-1$, then you can say:

$$
\begin{aligned}
& k_{\mathrm{t}}=\frac{x_{\mathrm{t}}+c_{\mathrm{t}}}{c_{\mathrm{t}-1}}-1 ; \mathrm{t}=1,2,3, \ldots, \mathrm{n} \\
& \operatorname{AIRR}(X)=\frac{1}{n} \sum_{t=1}^{n} k_{\mathrm{t}}
\end{aligned}
$$

\section{Net Investment Flows}

If the cash flow $X$ is $X=\left(x_{0}, x_{1}, x_{2}, x_{3}, \ldots, x_{n-1}, x_{n}\right)$ and $\mathrm{PV}(\mathrm{X} \mid \mathrm{r})>0 . X$ will be net investment flows .[4]

\section{The Net Borrowing}

If the cash flow of $X$ is $\mathrm{X}=\left(\mathrm{x}_{0}, \mathrm{x}_{1}, \mathrm{x}_{2}, \mathrm{x}_{3}, \ldots, \mathrm{x}_{\mathrm{n}-1}, \mathrm{x}_{\mathrm{n}}\right)$ and $\mathrm{PV}(\mathrm{X} \mid \mathrm{r})<0, X$ is a net borrowing .[4]

Theorem(2):For each desired investment flows of $C$ we will have:

A) If $\boldsymbol{P V}(\boldsymbol{C} \mid \boldsymbol{r})>0$ be (net investment), the following equation is established $\boldsymbol{P V}(\boldsymbol{X} \mid \boldsymbol{r}) \geq \mathbf{0}$ If and only if $\overline{\boldsymbol{k}}>\boldsymbol{r}$.

B) If $\boldsymbol{P} \boldsymbol{V}(\boldsymbol{C} \mid \boldsymbol{r})<0$ be (net borrowing), the following equation is established $\boldsymbol{P V}(\boldsymbol{C} \mid \boldsymbol{r}) \geq \mathbf{0}$ If and only if $\overline{\boldsymbol{k}}<\boldsymbol{r}$.

C) If $\boldsymbol{P} \boldsymbol{V}(\boldsymbol{C} \mid \boldsymbol{r})=\mathbf{0}$ be (Neutral), the following equation is established $\boldsymbol{P V}(\boldsymbol{C} \mid \boldsymbol{r})=\mathbf{0}$ if and only if $\overline{\boldsymbol{k}}=\boldsymbol{r}$.

\section{Determining the economic feasibility of the project using the approach of average rate of return on domestic capital (AIRR)}

Step(1): consider a desired investment flow $C=$ $\left(c_{0}, c_{1}, \ldots, c_{n-1}\right)$
Step(2): to obtain the vector for interest rates using the equation $k_{t}=\frac{x_{t}+c_{t}}{c_{t-1}}-1$

Step(3): Using equation (6 or 7) we will obtain average Internal Rate of Return on investment $(\bar{k})$ earned, and considering the Theorem(2) we can determine the project being economic or non-economic.

\section{Ranking projects by the help of AIRR}

A) Suppose we want to rank the projects $\mathrm{X}^{1}, \mathrm{X}^{2}, \ldots, \mathrm{X}^{\mathrm{m}}$ respectively with long lives of $n_{1}, n_{2}, \ldots, n_{m}$ with cash flow of $x_{0}$ in zero year (the launch period). We define the quantity $n$ as $n=\max \left\{n_{1}, n_{2}, \ldots, n_{m}\right\}$. Now to rank all projects we must define all periods of cash flows to the length of $n$. This requires that we obtain the number of projects that have less periods than $n$ by adding a zero to the end of their cash flow in the length of $n$.

B) If the project you want to have $x_{0}$ ratings are unequal to this problem must be to the quantity $\tilde{x}=\max \left\{x_{0}^{1}, x_{0}^{2}, \ldots, x_{0}^{m}\right\}$ define. Cash flow problems that $x_{0}$ which is less than $\tilde{x}$ by adding cash flow to cash flow projects help solve $\mathrm{Z}^{\mathrm{i}}$ so that $\mathrm{Z}^{\mathrm{i}}$ is equal to[9]:



It is clear that:

$$
P V\left(X_{\text {new }}^{\mathrm{i}} \mid r\right)=P V\left(X^{\mathrm{i}} \mid r\right)
$$

\section{Providing a New Approach}

Due to the relationships in the Theorem(1) and Theorem(2) we see that the rate of return calculation period is always in need of help, such as $C$ can be a cash flow.

Theorem(3): If cash flow $\mathrm{X}=\left(\mathrm{x}_{0}, \mathrm{x}_{1}, \mathrm{x}_{2}, \mathrm{x}_{3}, \ldots, \mathrm{x}_{\mathrm{n}-1}, \mathrm{x}_{\mathrm{n}}\right)$ and $\mathrm{r}$ is given by fixed capital costs and rates of return period $\left(k_{t}\right)$ to help cash flow $C=\left(c_{0}=-x_{0}, c_{1}=-x_{0}(1+\right.$ $r, c 2=-x 01+r 2, c 3=-x 01+r 3 \ldots, c n-1=-x 01+r n-1 \mathrm{Be}$ calculated, then: [ Aouthor]

$$
\left\{\begin{array}{l}
k_{\mathrm{t}}=\frac{\mathrm{x}_{\mathrm{t}}}{-\mathrm{x}_{0}(1+\mathrm{r})^{\mathrm{t}-1}}+\mathrm{r} ; 1 \leq \mathrm{t} \leq \mathrm{n}-1 \\
k_{n}=\frac{x_{n}}{-x_{0}(1+r)^{n-1}}-1
\end{array}\right.
$$

\section{Confirmed the first case:}

Suppose $1 \leq t \leq n-1$ is, as a result of the Theorem(1) can be said:

$$
k_{\mathrm{t}}=\frac{x_{\mathrm{t}}+c_{\mathrm{t}}}{c_{\mathrm{t}-1}}-1 ; 1 \leq t \leq n-1
$$

The supposed know that

$$
c_{t}=-x_{0}(1+r)^{t} ; 1 \leq t \leq n-1
$$

By substituting equation (13) in (12) we have:

$$
\begin{aligned}
& k_{t}=\frac{x_{\mathrm{t}}-x_{0}(1+r)^{t}}{-x_{0}(1+r)^{t-1}}-1 ; 1 \leq t \leq n-1 \\
& k_{\mathrm{t}}=\frac{x_{\mathrm{t}}}{-x_{0}(1+r)^{t-1}}+1+r+-1 ; 1 \leq t \leq n-1 \\
& k_{\mathrm{t}}=\frac{x_{\mathrm{t}}}{-x_{0}(1+r)^{t-1}}+r ; 1 \leq t \leq n-1
\end{aligned}
$$

End of Confirmed the first case.

Third case proof:

Suppose $t=n$, according to the result of the Theorem(1) can be said: 


\section{International Journal of Science and Research (IJSR) \\ ISSN (Online): 2319-7064}

Index Copernicus Value (2013): 6.14 | Impact Factor (2015): 6.391

The supposed know that:

$$
k_{n}=\frac{x_{n}+c_{n}}{c_{n-1}}-1
$$

$$
\left\{\begin{array}{l}
c_{n}=0 \\
c_{n-1}=-x_{0}(1+r)^{n-1}
\end{array}\right.
$$

By substituting equation (18) in (17) we have:

$$
k_{n}=\frac{x_{n}}{-x_{0}(1+r)^{n-1}}-1
$$

End of Confirmed the Third case.

The decision to establish and prove it all.

\section{Numerical example(1)}

Given the constant cost of capital to the amount of 5\% going to infrastructure projects using our new approach rating

$$
\left\{\begin{array}{l}
X^{1}=(-100,60,10,10,20) \\
X^{2}=(-100,40,0,80,0) \\
X^{3}=(-100,113,10,0,0)
\end{array}\right.
$$

Calculated in accordance with the new approach:

Table 1: This table rates of return period and the average Internal Rate of Return of capital for each of the projects we

\begin{tabular}{|c|c|c|c|c|c|c|c|}
\cline { 2 - 8 } \multicolumn{1}{c|}{} & $k_{1}$ & $k_{2}$ & $k_{3}$ & $k_{4}$ & AIRR & PV & Rank \\
\hline$X^{1}$ & 0.65 & 0.14 & 0.14 & -0.82 & 0.02 & -8.69 & 3 \\
\hline$X^{2}$ & 0.45 & 0.05 & 0.77 & -1.00 & 0.06 & 7.20 & 2 \\
\hline$X^{3}$ & 1.18 & 0.14 & 0.05 & -1.00 & 0.09 & 16.68 & 1 \\
\hline
\end{tabular}

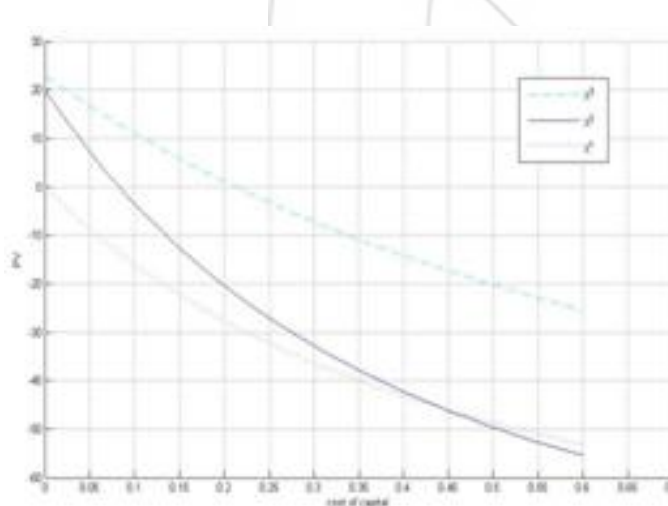

Figure 1: Graphs the present value of cash flows prior to depict.

\section{Numerical example (2)}

Given the constant cost of capital to the amount of 5\% going to infrastructure projects using our new approach rating $\left\{\begin{array}{l}X^{1}=(-100,10,35,-21,30,21,12,-25) \\ X^{2}=(0,100,15,-21,-30,50,-12,-29) \\ X^{3}=(10,-100,-15,-21,60,50,32,0)\end{array}\right.$

$$
\begin{aligned}
& \left\{\begin{array}{l}
\tilde{x}=10 \\
Z^{1}=(110,0,0,0,0,0,0,-154.7810) \\
Z^{2}=(10,0,0,0,0,0,0,-14.0710) \\
Z^{3}=(0,0,0,0,0,0,0,0)
\end{array}\right. \\
& \left\{\begin{array}{l}
X_{\text {new }}^{1}=(10,10,35,-21,30,21,12,-179.7810) \\
X_{\text {new }}^{2}=(10,100,15,-21,-30,50,-12,-43.0710) \\
X_{\text {new }}^{3}=(10,-100,-15,-21,60,50,32,0)
\end{array}\right.
\end{aligned}
$$

Calculated in accordance with the new approach:

Table.2

\begin{tabular}{|l|c|c|c|}
\cline { 2 - 4 } \multicolumn{1}{c|}{} & $A I R R$ & $P V$ & Rank \\
\hline$X_{\text {new }}^{1}$ & 0.7182 & -44.5480 & 3 \\
\hline$X_{\text {new }}^{2}$ & -1.0845 & 75.6338 & 1 \\
\hline$X_{\text {new }}^{3}$ & 0.1185 & -4.5668 & 2 \\
\hline
\end{tabular}

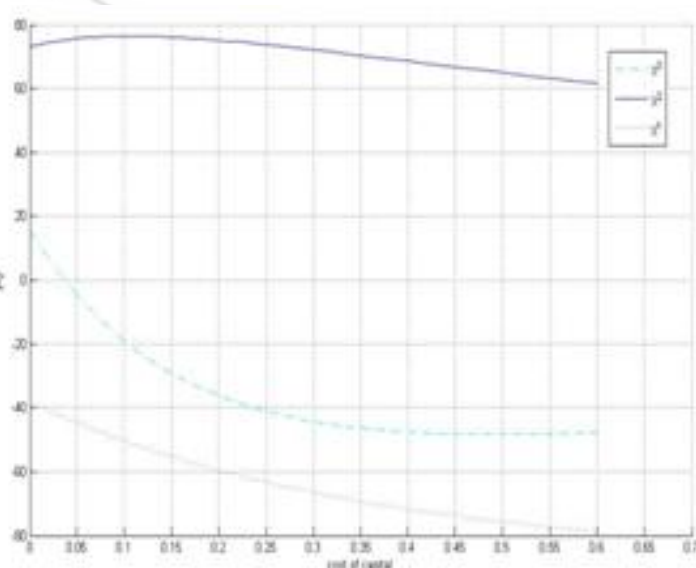

Figure 2: graphs the present value of cash flows prior to depict.

\section{Conclusion}

Some managers and decision makers are several reasons to use methods such as internal rate of return compared to the current value method more likely to show. However, the internal rate of return method is associated with many problems, including the rate. Magni method is a good solution to solve the problems of internal rate of return method. In this paper we present a simple case discussed As a result of the number of steps and volume calculations can be directly dropped Magni approach to calculate the return rates of pay.

\section{References}

[1] Arnold, G. Corporate financial management, 4th edition, London, Prentice Hall. Engineering economist, 46 (4), 322-311, 2004.

[2] Dean, A., \& Magni, C.A. Why IRR is Not the Rate of Return for Your Investment: Introducing AIRR to the Real Estate Community, Journal of Real Estate Portfolio Management ,18 (2), 219-230, 2012.

[3] Farragher, E.J., Kleiman, R.T., \&Sahu, A.P. The association between the use of sophisticated capital 


\section{International Journal of Science and Research (IJSR) \\ ISSN (Online): 2319-7064}

Index Copernicus Value (2013): 6.14 | Impact Factor (2015): 6.391

budgeting practices and corporate performance, the engineering economist, 46 (4), 322-311, 2011.

[4] Hazen, G. A new perspective on multiple internal rate of return. The Engineering Economist ,43(1),31-51, 2003.

[5] Hirschey , M. Managerial economics , 12th edition , Ohio, Thomson-south western, 2009.

[6] Michael, J . The Quarterly Review of Economics and Finance . The Quarterly Review of Economics and Finance , 50, 234-239, 2010.

[7] Magni, C.A. Average internal rate of return and investment decisions: a new perspective.Engineering Economist , 23 (3), 10-31, 2010.

[8] Norstrøm, C. Modification of the Internal Rate of Return Methodl. StatsØkonomisk Tidsskrift nr ,4, 214-231, 1971.

[9] Russell, M., \& Rickard, J . Uniquenss of non-negative internal rate of return. JIA ,109,435-445, 1982.

\section{Author Profile}

Hossein Jafari is member of Young Researchers and Elite Club and Teacher at the SID. The researchers have so far succeeded in publishing several articles in journals has been ISI.

Volume 5 Issue 7, July 2016 www.ijsr.net 